\title{
Cardiovascular risk guidelines and transparency
}

\author{
Edward Davies US news and features editor
}

The importance of transparency with regards to author and industry ties when publishing research is paramount. The degree of disclosure and what exactly constitutes a competing interest will vary by author and journal, but its impact on independence, either perceived or real, is universally acknowledged.

Also acknowledged but far less widely discussed are the interests of those sitting on clinical guideline panels and the lack of consensus on what is acceptable is a problem. While many guideline panels will base their decisions on the best available evidence, panels are the filter through which the small academic community can disseminate evidence based medicine to the much larger, worldwide physician audience. If that filter is conflicted it can have a major impact on patient care.

If the two paragraphs above sound familiar, that is because I wrote them for an Editor's Choice article just two months ago (doi:10.1136/bmj.f5733). But this week they need to be repeated and re-emphasised.

The new guidelines on cardiovascular risk (doi:10.1136/bmj. f6858) drawn up by panels from the American Heart

Association, the American College of Cardiology, and the Obesity Society have been subject to fierce criticism since their release last week, with some experts claiming that millions more people will be prescribed statins as a result (doi:10.1136/bmj. f6957).
Criticism of any new guidelines is absolutely healthy and no cause for concern. It is now reported, however, that more than half the panelists working on the guidelines-described by observers as "a big kiss to big pharma"- -had substantial ties with industry (doi:10.1136/bmj.f6989).

This is absolutely not a slur on the integrity or ability of those sitting on this or other similar panels, who often do a terrific and difficult job. But when criticism inevitably comes in these situations, such clear financial ties muddy the waters of transparency, when they need not even exist in the first place. Can we no longer find 15 experts in the entire United States without financial links to industry?

Just two months ago, the $B M J$ published a manifesto on how to prevent this problem, in which a large group of international experts proposed a framework for change (doi:10.1136/bmj. f5535). At the time I described it as imperfect but demanding serious consideration. I would now add that in light of these continuing concerns, the serious consideration should start with some urgency.

Cite this as: BMJ 2013;347:f7022

๑) BMJ Publishing Group Ltd 2013 